\title{
Correspondence
}

\section{Exceptions to Bradford's Law}

Sir,-The selection of periodicals for subscription is a considerable problem to libraries who want to make the most of available resources of money and manpower for processing. Goffman and Morris (Nature, June 6, 1970, p. 922) suggest the use of Bradford's law of dispersion as an aid to selection decision, and this appears to be a most promising method.

However, one important factor has been omitted in their considerations, probably because it is difficult to quantify. It is the possibility that a very specialized journal is of interest to only one user to whom it is, however, vital. Such a journal might well be discontinued, using Goffman and Morris's reasoning, especially if it is a new journal initially consulted by several users but then dropped.

On the other hand, there are journals dealing, not very profoundly, with a rather wide subject range which might contain items of interest to a larger number of users, though they probably would not miss it if it were no longer easily available. Such a journal would not be discontinued, even if money was short.

Before it is possible to discontinue a journal subscription, it is necessary to make sure that such action will not cause great inconvenience.

\section{Yours faithfully,}

\section{A. Fasleer}

Department of Research,

Reckitt and Colman,

Norwich NOR 75A.

\section{Stoned Assents}

SrR,- - I find it necessary to criticize the report on marijuana intoxication (Nature, 226, 701; 1970), by Charles Tart, which was based on a 20 per cent reply to "about 750 " questionnaires distributed by students to unknown persons.

It would seem that at least 53 per cent of these "experienced" users just ticked off "yes" to every positive question. This is indicated by the following contradictions:

My memory of what went on is better than if I had been straight, 55 per cent.

My memory of what went on while I was stoned is poor afterwards, 57 per cent.

Distances between me and things or me and other people seem to get greater, 69 per cent.

Distances seem to get shorter, 53 per cent.

Although no conclusions were drawn, a quick reading of the report would give the impression that the effects of marijuana are overwhelmingly positive. However, it seems significant that 80 per cent found it difficult to read, and that 83 per cent found it very hard to play ordinary social games.

\section{Yours faithfully,}

\section{RICHARD T. BARRETT}

The Pottery Plus,

Old Fore Street,

Sidmouth, Devon.

\section{Ambiguous Mustard}

SrR,-Following the publication of the most interesting papers of Pearson and Bobrow ${ }^{1}$ and of Barlow and Vosa ${ }^{2}$ I am prompted to point out that the trivial name "quinacrine mustard" has been used in publications to describe at least two chemical species namely, 2-methoxy-6-chloro9-[4-bis(2-chloroethyl)amino-1-methyl-butylamino] acridine (Compound I) and 2-methoxy-6-chloro-9-[3-(ethyl-2chloroethyl) amino-propylamino] acridine (Compound II).
Since quinacrine, or, atebrine, is 2-methoxy-6-chloro-9(4-diethylamino-1-methyl-butylamino) acridine it would have seemed preferable to have reserved the name for Compound I. Consultation of their references shows that this was indeed the substance used by the aforementioned authors under the name of "quinacrine mustard."

Compound II was originally prepared at the Institute for Cancer Research, Philadelphia, where it was given the code No. ICR-100, later amended to ICR-170. This substance has been used by many workers for genetic studies and has often also been referred to as "quinacrine mustard". I, too, have contributed to this confusion.

The ambiguity would, perhaps, have been unimportant if the difference between the two compounds had lain only in their primary alkyl side-chains; however, it should be noted that Compound $\mathrm{I}$ is a disfunctional and Compound II a monofunctional "nitrogen mustard".

Creech $^{3}$ has referred to the two substances as "Quin. $\mathrm{M}$ (mobu).HCl" (Compound I) and "Quin. M. (propyl). HCl" (Compound II). May I therefore suggest that if authors wish to continue to use the expression "quinacrine mustard" this be restricted to the true quinacrine derivative, with or without an optional (methyl butyl form) qualification, and that Compound II be referred to as quinacrine mustard (mono-functional propyl analogue) and its chemical name spelled out.

$$
\begin{aligned}
& \text { Yours sincerely, } \\
& \text { Anthony Loveless }
\end{aligned}
$$

Institute of Cancer Research,

Chester Beatty Research Institute,

Fulham Road,

London SW3.

${ }^{1}$ Pearson, P. L., and Hobrow, M., Nature, 228, 959 (1970).

2 Barlow, P., and Vosa, C. G., Nature, 226, 961 (1970).

${ }^{3}$ Creech, H. J., Ann. NY Acad. Sci., 68, 868 (1958).

\section{Nuclear Activity}

Sir,--I am writing to point out that there are two errors in your correspondent's report of the British Society for Cell Biology meeting on the control of nuclear activity (Nature, 226, 406; 1970).

The apparatus used in our experiments provided a microbeam of ultraviolet-radiation, and not X-radiation as stated by your correspondent. It is already well known that non-ionizing ultraviolet and ionizing $\mathrm{X}$-rays can produce quite different biological results.

Furthermore, the sentence implies that microbeam irradiation of the nucleolus or the nucleoplasm does not affect DNA synthesis. On the contrary, at certain doses, microbeam irradiation does drastically reduce DNA synthesis. The point to be made is that the results show that the nucleolus does not appear specifically to control the onset of DNA synthesis.

$$
\text { Yours faithfully, }
$$

Department of Radiotherapeutics,

John Hatfield

University of Cambridge,

Tennis Court Road,

Cambridge.

Our correspondent writes: Dr Hatfield is quite justified in complaining of the substitution of X-radiation for ultraviolet radiation. I am only too well aware of the different biological results produced by ionizing and non-ionizing radiation. The words "initiation of" (DNA synthesis) were omitted by me from my transcript of the report, despite the fact that they were contained in the abstract of his paper. I am sorry that these mistakes crept into. my comments. 